\title{
Energy Performance of Medium-sized Healthcare Buildings in Victoria, Australia- A Case Study
}

\author{
Priyadarsini Rajagopalan* and Hisham Elkadi \\ School of Architecture and Built Environment, \\ Deakin University, Australia
}

Submitted August 2013. Accepted for publication February 2014.

\begin{abstract}
This paper investigates the energy performance of three medium-sized healthcare buildings in Victoria, Australia, that operate only during the daytime. The aim is to provide preliminary understanding of energy consumption in this particular typology in Australia in relation to the available benchmarks. This paper also identifies the differences of energy consumption between different functional areas within medium health facilities. Building features and operational characteristics contributing to the variations in healthcare energy performance are discussed. The total annual energy consumption data ranging from $167-306 \mathrm{kWh} / \mathrm{m}^{2}$ or $42-72 \mathrm{kWh} / \mathrm{m}^{3}$ were compared against international data from various climatic zones. Some of the drivers of energy consumption were determined and potentials for energy and water conservation were identified. Comparison with international standards shows a possibility to achieve lower energy consumption in Victorian healthcare buildings.
\end{abstract}

Keywords: medium-sized health centre, Energy, benchmarking.

\section{INTRODUCTION}

Healthcare buildings generally have high energy demand $[1,2]$. A number of studies, in US and UK, attempted to set up energy benchmarks for these facilities to assist in the future energy efficient design [3-9]. In the United States, a guide was prepared to provide a simple prescriptive path to $30 \%$ saving over Standard 90.1-1999 of small healthcare facilities $[3,4]$. The ultimate goal is to achieve net zero energy building. The country was divided into different climatic zones and low energy models were devised based on recommended energy efficiency measures. The recommendations have led to greater than $30 \%$ saving in all climatic zones. In UK, the National Health Service (NHS) is a major contributor to carbon emissions. Statistics recently published by the NHS Sustainable Development Unit [5] reveal

*Corresponding author: 1, Gheringhap Street, Geelong, 3217, VIC, Australia. E mail: priya@deakin.edu.au. Other author: E-mail: hisham.elkadi@deakin.edu.au. 
that NHS is responsible for more than 18 million tonnes of carbon dioxide emission per annum. This constitutes about $3 \%$ of UK carbon dioxide emissions and $30 \%$ of public sector emissions, with annual costs of $£ 429$ million just for heating and lighting. UK healthcare facilities are audited on an annual basis to monitor energy performance, which is measured in terms of GJ of energy used per 100 cubic metres of treated building volume $\left(\mathrm{GJ} / 100 \mathrm{~m}^{3}\right)$. Premises are classified according to the results and a benchmark was set for all existing healthcare buildings to meet a target of $15,278-18,056 \mathrm{kWh} / 100 \mathrm{~m}^{3}$ [6]. New premises are required to achieve a benchmark of $9,720-12,501 \mathrm{kWh} / 100 \mathrm{~m}^{3}$. A recent study by a Cambridge University research team investigated the opportunities for reducing NHS energy consumption by incorporating low-energy ventilation and cooling strategies into the design of new hospitals and the refurbishment of existing facilities [7, 8, 9]. The study suggests that it is possible to achieve an energy consumption of $10,556 \mathrm{kWh} / 100 \mathrm{~m}^{3}$ per annum for a representative selection of rooms located South of England. The current energy performance of the majority of NHS trusts in England varies between $12,444-27,222 \mathrm{kWh} / 100 \mathrm{~m}^{3}$. In Scotland, Murray et al. [10] attempted to create an energy benchmark target to investigate the environmental impacts of small healthcare buildings and the scope for improvements. It was found that "energy consumption varied widely between different centres but this variation could not be linked to building style, floor area or volume. Overall, it was found that a benchmark of $56 \mathrm{kWh} / \mathrm{m}^{3}$ would be challenging, but realistic" (p.1236). In a study of 978 municipal service facilities in Barcelona, Oliver-Sola et al. [11] reported energy consumption ranging from $36.8 \mathrm{kWh} / \mathrm{m}^{2}$ to $262.5 \mathrm{kWh} / \mathrm{m}^{2}$ with an average of $95 \mathrm{kWh} / \mathrm{m}^{2}$ for small healthcare centres.

The healthcare system in Australia is clearly classified into public and private hospitals. Public hospitals in Australia are funded by the commonwealth, states and territory governments. The operation and organization of the health service is provided by the department of health in each state or territory. Short term acute care is provided in public hospitals. However some services such as rehabilitation are provided on long term basis. Psychiatric hospitals are specialised in mental health issues. In total, there are around 1326 hospitals in Australia including day facilities in which 753 are public and 523 are private. Victoria has 311 hospitals. Primary health care is mainly delivered in more than 7,000 General Practices (GP) across Australia. These include community healthcare centres consisting of community health, dental and mental health services. There are approximately 100 Community Healthcare Centres in Victoria operating from approximately 350 sites. Healthcare sector is a major part of the economy with an expenditure of US \$92 billion in 2009 in comparison to US $\$ 10.8$ billion in 1981-82 [12]. Healthcare facilities present major sustainability challenge as their energy intensity is twice and water usage is around six times that of commercial office buildings. The healthcare sector alone is responsible for 4.1 Mt of green-house gas emissions per year which accounts for $13 \%$ of the total building sector [13]. This is lower compared to UK due to various reasons such as low population, less number of hospitals and less severe climatic conditions. Australia's ageing population will put further pressure on healthcare 
facilities in the coming decades as more people will fall into the older age group that needs to use the healthcare system more frequently. Therefore, there will be a need to plan for infrastructure to accommodate the demand. There is an increasing number of smaller size healthcare facilities to cater for the long waiting period in public hospitals in Australia. Despite the rapid growth in these facilities, there is limited research on the environmental performance of medium-sized healthcare facilities in Australia. This paper investigates the energy performance of three medium-sized healthcare buildings in Victoria, Australia.

\section{METHODOLOGY}

\subsection{Method Outlines}

Energy benchmarking is a good tool to inform buildings of their relative standings in the comparison group and sets achievable goals for improvements. In order to set up targets, a clear understanding of the current energy use must be firstly obtained. The data regarding physical, operational and occupancy characteristics as well as site energy consumption of three medium-sized healthcare facilities were collected to identify the key indicators of energy consumption. In addition, energy simulations were conducted to investigate the consumption by different sub-systems and recognise the saving potentials. Each building is evaluated based on a number of criteria such as physical, occupancy and energy consumption. The physical data including architectural design and form, floor area, volume, construction materials, details of heating, ventilation and air conditioning (HVAC) equipment etc. were collected from the building floor plans, elevations, sections, mechanical drawings, and building management system (BMS) system. This was followed by a detailed walk through to all the spaces within the building. Occupancy characteristics were collected from the staff records and patient registers. The energy consumption data for a year were collected from monthly energy bills and energy use intensity, which is the energy consumption per unit floor area, are compared.

\subsection{Characteristics of Medium-Sized Healthcare Buildings}

"Medium size" healthcare buildings are not well defined in Australia. However, the characteristics of such buildings are somewhere in between "community and mental care hospitals" and "health centres and clinics" as classified by National Health Service (NHS) UK and similar to small surgery centres in US. They operate only during the day and their floor areas range between 1000 and $4000 \mathrm{~m}^{2}$. Three medium-sized health care facilities under the public healthcare sector in regional Victoria were investigated. One of these buildings are relatively new and the other two are more than 20 years old.

\subsubsection{Physical and Occupancy Characteristics}

Table 1 shows a summary of the physical and occupancy characteristics of the three study buildings. Building 1 constructed in 1980s, is the oldest among the three buildings. The building is single storey, expanding across $1366 \mathrm{~m}^{2}$ floor area in a relatively traditional box form and pitched roof. Building structure is brick veneer 
Table 1. Physical and occupancy characteristics of the buildings

\begin{tabular}{lccc}
\hline & Building 1 & Building 2 & Building 3 \\
\hline $\begin{array}{l}\text { Construction } \\
\text { year }\end{array}$ & 1980 's & 2001 & $1980 \mathrm{~s}$ \\
Opening hours & 5 days per week & 5 days per week & 5.5 days per week. \\
& $(43$ hours $)$ & $(43$ hours $)$ & $(48$ hours $)$ \\
Floor Area & $1366 \mathrm{~m}^{2}$ & $1996 \mathrm{~m}^{2}$ & $3292 \mathrm{~m}^{2}$ \\
Volume & $5355.00 \mathrm{~m}^{3}$ & $8525.2 \mathrm{~m}^{3}$ & $13991.00 \mathrm{~m}^{3}$ \\
Cooling & Reverse cycle & Central Air- & Central Air- \\
& & conditioning with & conditioning with \\
& & chiller & chiller \\
Heating & Reverse cycle & Gas boiler & Gas boiler \\
Skylight & Exists, but blocked & Circular shaft in the & NA \\
& in some areas & centre core &
\end{tabular}

on a concrete slab. There are around 25 people working in this centre (including part time and casual) from 8.30 am to $5.00 \mathrm{pm}$ Monday to Friday.

Building 2, built in 2001 has a circular shaped core with high ceiling and six separate wings extended out of its centre. It is a single storey brick veneer construction on concrete slab. The main entrance of the building faces North. The design of the building allows every room to be lit with natural light. The ceiling of the central circular core is lifted up by about 2 meters to allow natural light to flow in.

Building 3, built in 1980s and refurbished with new HVAC system in 2002, is the largest among the three selected buildings with a total floor area of $3292 \mathrm{~m}^{2}$ in a single storey. It is orientated North-West to South-East with most of its major openings facing South-West and North-East. Building structure is brick veneer over a concrete slab with slightly pitched roof rising to form the main entrance. The information regarding the total number of staff and patients were not easily available. The number of staff varied day by day as many staff work part time. The numbers of people per unit floor area are similar in the three buildings.

\subsubsection{Building Fabric and Type of Functional Spaces}

The main functional areas in the buildings were categorised into 6 different categories as per their energy usage intensity. They are offices and circulation spaces, mental health, community health, dental and renal (see Table 2). The surface area of the walls and windows were measured from the building drawings in order to calculate the percentage of external exposure (Table 3). Building 2 has the largest envelope area because of the long wings. It was noted that building 3 which is the largest, has the smallest envelope area because of the compact design. Compactness ratio, one of the most important related to energy losses that need to be compensated by HVAC system operation, was calculated by dividing the envelope area by 
Table 2. Types and areas of functional spaces

\begin{tabular}{ccccc}
\hline Categories & Space type & Building $\mathbf{1}$ & Building 2 & Building 3 \\
\hline 1 & Circulation and office & $44.8 \%$ & $38.5 \%$ & $34.2 \%$ \\
2 & Mental health & $13.8 \%$ & $14 \%$ & $13.8 \%$ \\
3 & Community & $25.41 \%$ & $16.8 \%$ & $29.2 \%$ \\
& health and & & & \\
& physiology & & & \\
4 & Dental & $9.57 \%$ & $17.2 \%$ & $15.7 \%$ \\
5 & Renal & $0.00 \%$ & $11.5 \%$ & $0.00 \%$ \\
6 & Others & $6.35 \%$ & $2 \%$ & $6.35 \%$
\end{tabular}

Table 3. Area and thermal properties of envelope

\begin{tabular}{|c|c|c|c|c|c|c|}
\hline & $\begin{array}{c}\text { Wall area } \\
\text { exposed }\end{array}$ & $\begin{array}{c}\text { Window } \\
\text { area } \\
\text { exposed }\end{array}$ & $\begin{array}{l}\text { U value } \\
\mathbf{W} / \mathbf{m}^{2}-\mathbf{K}\end{array}$ & $\begin{array}{c}\text { Window/ } \\
\text { wall }\end{array}$ & $\begin{array}{c}\text { Compactness } \\
\text { (envelope } \\
\text { area/volume) }\end{array}$ & $\begin{array}{c}\text { Building } \\
\text { plan }\end{array}$ \\
\hline Building 1 & $241.1 \mathrm{~m}^{2}$ & $132.3 \mathrm{~m}^{2}$ & & $55 \%$ & 0.070 & \\
\hline Building 2 & $351.1 \mathrm{~m}^{2}$ & $145 \mathrm{~m}^{2}$ & $\begin{array}{c}2.12 \text { (walls) } \\
3.68 \text { (windows) } \\
1.62 \text { (roof) }\end{array}$ & $41 \%$ & 0.058 & \\
\hline Building 3 & $261.8 \mathrm{~m}^{2}$ & $88.5 \mathrm{~m}^{2}$ & & $34 \%$ & 0.025 & \\
\hline
\end{tabular}

volume. Building 1 has the largest compactness ratio which means there is more heat gain and loss through the envelope. Building 3 has the smallest compactness ratio.

\subsubsection{Climatic Conditions}

Victoria is located at latitude $37^{\circ} 78^{\prime} \mathrm{S}$, longitude $144^{\circ} 97^{\prime} \mathrm{E}$, and enjoys a temperate climate with warm to hot summers, mild springs and autumns, and cool winters. The summer season is from December to February when the weather remains sunny, with average wind speed of $22 \mathrm{~m} / \mathrm{s}$ and the average maximum temperature of $25.5^{\circ} \mathrm{C}$ (Figure 1). The summer temperature can exceed $40^{\circ} \mathrm{C}$. In winter (June to August), Victoria experiences some of Australia's coldest weather. The average daily temperature during winter is $14^{\circ} \mathrm{C}$, and it can fall below $4^{\circ} \mathrm{C}$. Heating and cooling degree days are around 1036 and 762, respectively, for the year of this study. 


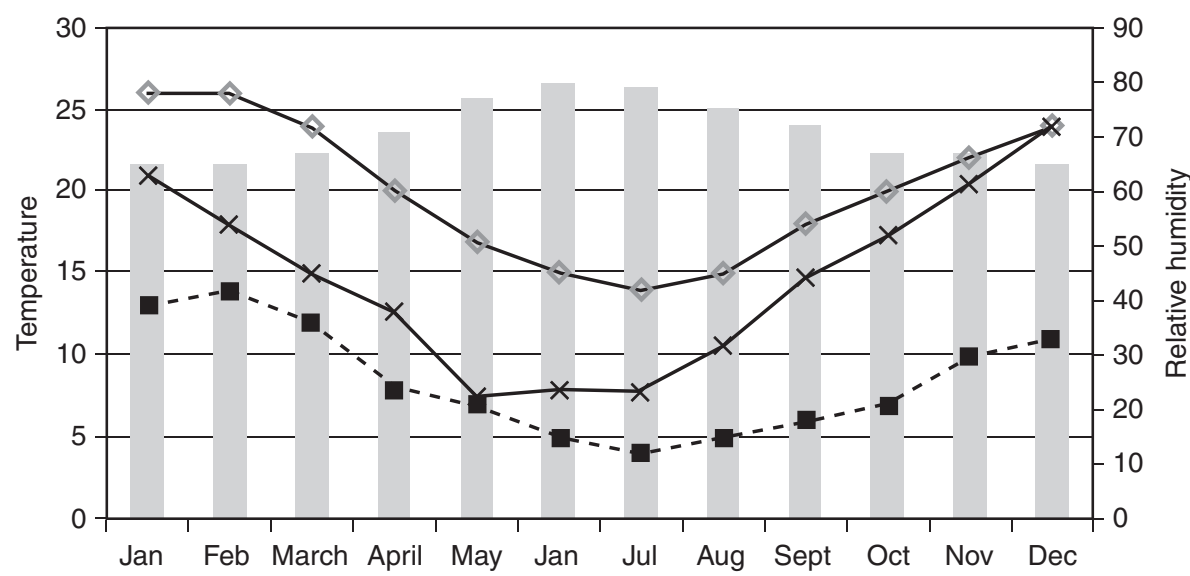

$\mathrm{RH}(\%)-\diamond-$ Max temp $(\infty \mathrm{C})-\mathbf{\square}-\operatorname{Min}$ temp $(\infty \mathrm{C}) \longrightarrow \leftarrow$ Solar radiation $(\mathrm{MJ} / \mathrm{sq} \cdot \mathrm{m})$

Figure 1. Weather data for Victoria.

\subsubsection{HVAC Systems}

Since all the three buildings were managed by the same public health organisation, the HVAC settings were very similar. Table 4 shows the detail of the HVAC system. Building 1 has many reverse cycle multi-split units, some of which are ducted and others standalone. The capacity of the ducted split systems ranged from 10-25 kW. Building 2 has a Mulistack chiller with $246 \mathrm{~kW}$ cooling. A Multistack chiller is a bank of individual chiller modules connected in parallel to operate as a single machine. In addition, building 2 has three split units in different rooms. Heating is provided by gas boilers with fan coils. The HVAC system for Building 3 consists of a centralised plant with $600 \mathrm{~kW}$ condensing units and number of small split units for backup. The temperature settings ranged from $20-23^{\circ} \mathrm{C}$. Mechanical ventilation rate varied between 6 to 10 air change rates $(\mathrm{ACH})$ as shown in the Table 4.

\section{RESULTS AND DISCUSSIONS}

\subsection{Energy Consumption}

Electricity, gas and water consumption data for a whole year for 2011 were collected from the three buildings using utility bills (Table 5). The electricity consumption ranged from $183,910 \mathrm{kWh}$ to $454,874 \mathrm{kWh}$ and gas consumption ranged from $33,611 \mathrm{kWh}$ to $269,444 \mathrm{kWh}$. It is to be noted that only site energy data are taken into consideration here. Electricity consumption data had a good correlation with floor areas and building volumes. Building 1, the smallest among the three has the lowest electricity and gas consumption. Electricity consumption can be normalised by dividing the consumption with the floor area. After normalising with floor area, building 2 has the highest electricity consumption per unit floor area. Both buildings 1 and 3 showed similar usage intensity, and building 1 had the lowest electricity consumption per unit floor area (Figure 2). 
Table 4. Details of HVAC systems

\begin{tabular}{lccc}
\hline & Building 1 & Building 2 & Building 3 \\
\hline & $\begin{array}{c}\text { 7 Air Handling Unit } \\
\text { (AHU) reverse cycle } \\
\text { ducted split systems }\end{array}$ & $\begin{array}{c}\text { The system uses } \\
\text { 8 A.H.U. single } \\
\text { zone systems }\end{array}$ & $\begin{array}{c}\text { Centralised plant } \\
\text { using a direct } \\
\text { expansion (DX) } \\
\text { chiller and } \\
\text { reheat coils }\end{array}$ \\
$\begin{array}{l}\text { Type of HVAC } \\
\text { system }\end{array}$ & 7.30 am to $5.30 \mathrm{pm}$ & 6 am to $9 \mathrm{pm}$ & 6 am to 9 pm \\
\hline $\begin{array}{l}\text { Operating time } \\
\text { Set point } \\
\text { temperature }\left({ }^{\circ} \mathrm{C}\right)\end{array}$ & $20-23$ & $20-23$ & $20-23$ \\
$\begin{array}{l}\text { Ventilation rate } \\
\text { (ACH/hour) }\end{array}$ & $6-10$ & $6-10$ & $6-10$ \\
$\begin{array}{l}\text { Supply air } \\
\text { temperature }\left({ }^{\circ} \mathrm{C}\right)\end{array}$ & 12 & 12 & 12
\end{tabular}

Table 5. Energy and water consumption

\begin{tabular}{lccc}
\hline & Building $\mathbf{1}$ & Building 2 & Building $\mathbf{3}$ \\
\hline Area $\left(\mathrm{m}^{2}\right)$ & 1,366 & 1,996 & 3,292 \\
Volume $\left(\mathrm{m}^{3}\right)$ & 5,355 & 8,525 & 13,991 \\
Electricity $(\mathrm{kWh})$ & 183,910 & 335,528 & 454,874 \\
Gas $(\mathrm{GJ})$ & 121 & 970 & 741 \\
Total GJ $/ \mathrm{m}^{3}$ & 1460 & 2560 & 1700 \\
Water $\left(\mathrm{m}^{3}\right)$ & 837 & 2,737 & 741
\end{tabular}

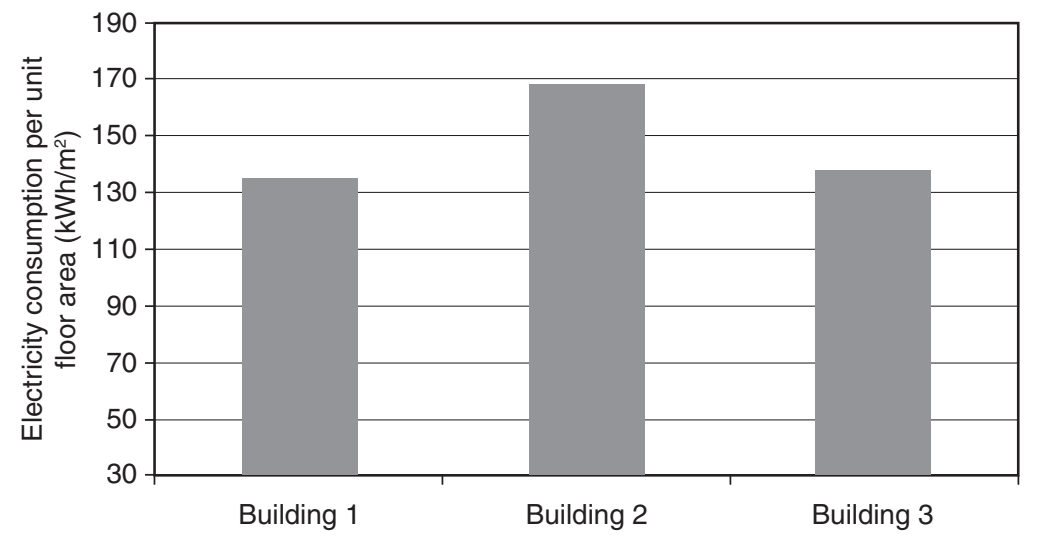

Figure 2. Electricity consumption. 
Though buildings 2 and 3 have water cooled chillers, the controls in each system work differently. For building 3, the supply air temperature is developed by AHU 1 centralised plant using a DX chiller and reheat coils. The system only starts operating in full capacity once all the zones are outside the set point temperature, whereas in building 2, the system starts operating in full capacity when any one of the zones is outside the set point temperature. As a result, the occupants in building 3 experience thermal discomforts and this was confirmed with the staff working in this building. The relatively smaller electricity consumption in building 3 in comparison to building 2 could be a consequence of compromised thermal comfort. A detailed thermal comfort measurement would be required to confirm this outcome.

Figure 3 shows the gas consumption per unit volume for the three buildings. Gas consumption of building 2 is significantly higher than buildings 1 and 3. As shown in table 2, building 2 has a large area for dental facilities. In addition, it has a renal unit comprising of $11.5 \%$ of the floor area which opens 5.5 days per week. Studies in UK showed that renal medicine is a carbon intensive speciality [14] and significant improvements could be made in the recapture of heat from renal equipment.

Figure 4 shows water consumption of three buildings normalised against floor area. Within healthcare buildings, the majority of water used is through taps, showers and toilet use (approximately 80\%). Food processing, water cooling units and renal dialysis also contribute to water consumption. Building 2 which has a renal unit has the highest water consumption. Reverse-osmosis renal dialysis units "reject" or discard water (30$50 \%$ of the original mains water used) that has passed through pre-dialysis water filtration before exposure to blood products. This high grade water can be preserved easily. For example, the water can be transferred to a storage using a pump and can be used to generate steam for sterilization units. The water can also be used to water the plants and in sanitation systems [15].

Observations conducted in Building 2 revealed that patients undergoing dialysis often feel very cold, as a result of which the set temperature needs to be increased. At the same time, the staff feel very hot and they will have to adjust their clothing

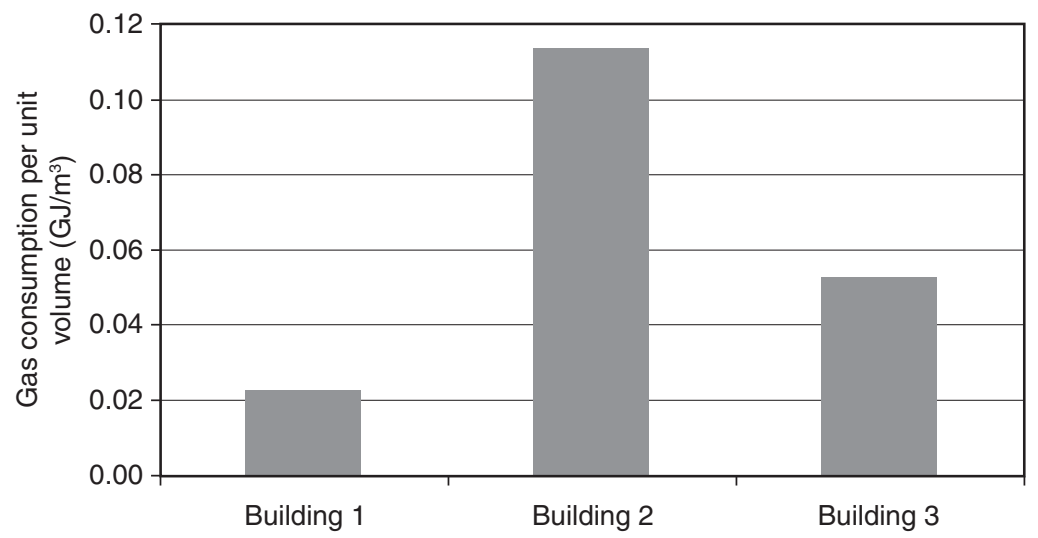

Figure 3. Gas consumption. 


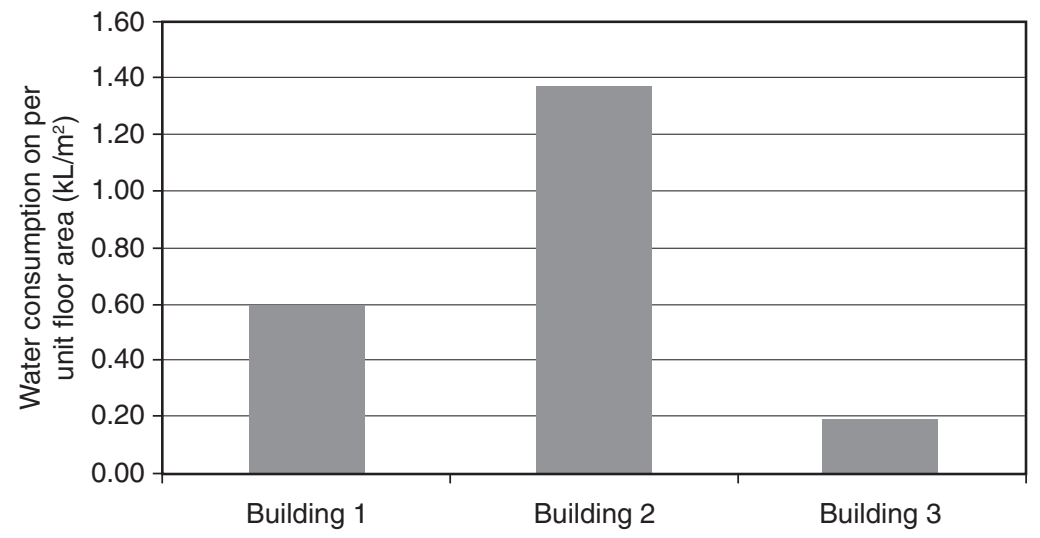

Figure 4. Water consumption.

to much lighter level in order to accommodate the high temperature. Another interesting fact to note is that buildings 1 and 2 have additional daylighting features in the form of skylights. However, the installation of artificial lights was not significantly different in these two buildings. In addition, no dimming system or lighting sensors were installed to optimise the use of daylighting. This is further discussed in the next section.

The total energy usage of the three buildings ranged from $167-306 \mathrm{kWh} / \mathrm{m}^{2}$. Estimating by treated volume, which is a major factor in energy consumption, resulted in $42-72 \mathrm{kWh} / \mathrm{m}^{3}$. Previous study on $180 \mathrm{C} 5$ buildings (small healthcare buildings such as health centres, clinics and dentists) in NHS Scotland, operating 47 hours per week, which is very similar to the buildings under study, revealed that the average annual energy consumption was $308 \mathrm{kWh} / \mathrm{m}^{2}$ with a surprisingly wide range of $76-1064 \mathrm{kWh} / \mathrm{m}^{2}$. Estimating by total heated volume gives an average consumption of $125 \mathrm{kWh} / \mathrm{m}^{3}$ with a range of $31-425 \mathrm{kWh} / \mathrm{m}^{3}$ per year [10]. However, it is to be taken into consideration that, compared to Scotland, Victoria has 1,613 less heating degree days (HDD) and 643 more cooling degree days (CDD), meaning that the weather is $54 \%$ less severe in Victoria. The results are further compared to the data from similar climatic conditions in U.S as specified in the advance energy design guide for small hospitals and healthcare facilities [4]. The total energy consumption data for small surgery centres were $494 \mathrm{kWh} / \mathrm{m}^{2}$ for baseline model and $270 \mathrm{kWh} / \mathrm{m}^{2}$ for the low energy case. The inclusion of operating room could have led to higher consumption in US surgery centres. Similarly in Barcelona, reported energy consumption for small healthcare centres ranged from $36.8 \mathrm{kWh} / \mathrm{m}^{2}$ to $262.5 \mathrm{kWh} / \mathrm{m}^{2}$ [11]. Again, it is to be noted that Victoria has 572 HDD and 242 CDD less than Barcelona, indicating that the weather is $45 \%$ less severe in Victoria. All these analysis indicate that there is great potential for energy saving in the Victorian healthcare buildings. 


\subsection{Energy Simulation}

Energy simulations were conducted using IES Virtual Environment [16]. The three buildings discussed above were modelled using Model IT and then simulated using the dynamic thermal simulation tool, ApacheSim. The lighting and equipment power densities were estimated to be ranging from 10 to $16.3 \mathrm{~W} / \mathrm{m}^{2}$ and from 15 to 30 $\mathrm{W} / \mathrm{m}^{2}$, respectively, as given in Table 6 .

Figure 5 shows the model for Building 2 developed in IES model IT. The simulation models were first calibrated using monthly utility data. Figure 6 shows the comparison between metered electricity consumption and simulated consumption for Building 2 . The maximum error was within $20 \%$. Energy consumption of the subsystems were analysed in terms of heating, cooling, equipment and lighting. Heating and cooling load components were further broken down to identify the influence of envelope, people and

Table 6. Lighting and occupant power density

\begin{tabular}{lcc}
\hline Functional Spaces & $\begin{array}{c}\text { Lighting Power } \\
\text { Density }\left(\mathbf{W} / \mathbf{m}^{\mathbf{2}}\right)\end{array}$ & $\begin{array}{c}\text { Equipment Power } \\
\text { Density }\left(\mathbf{W} / \mathbf{m}^{\mathbf{2}}\right)\end{array}$ \\
\hline Circulation \& Offices & 11.0 & 20.0 \\
Mental Health & 11.0 & 15.0 \\
Community Health \& Physio & 16.3 & 20.0 \\
Dental & 16.3 & 20.0 \\
Renal & 13 & 30.0 \\
Others & 9.9 & 15.0
\end{tabular}

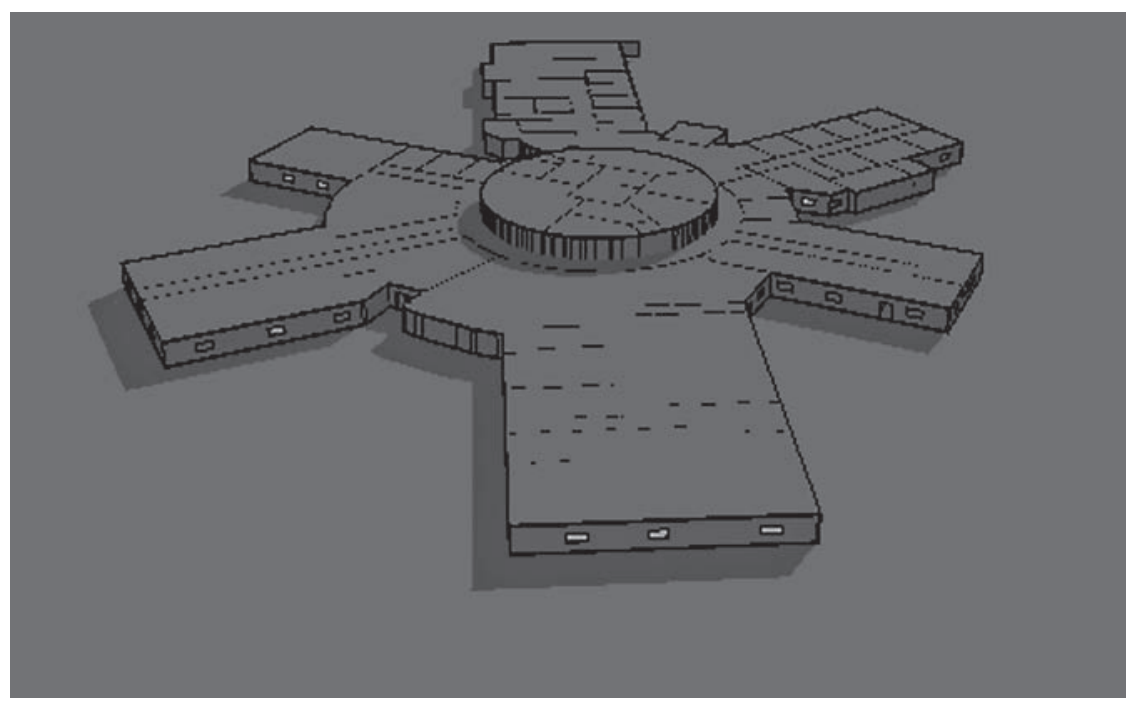

Figure 5. Model of Building 2 in IES Virtual Environment [19]. 


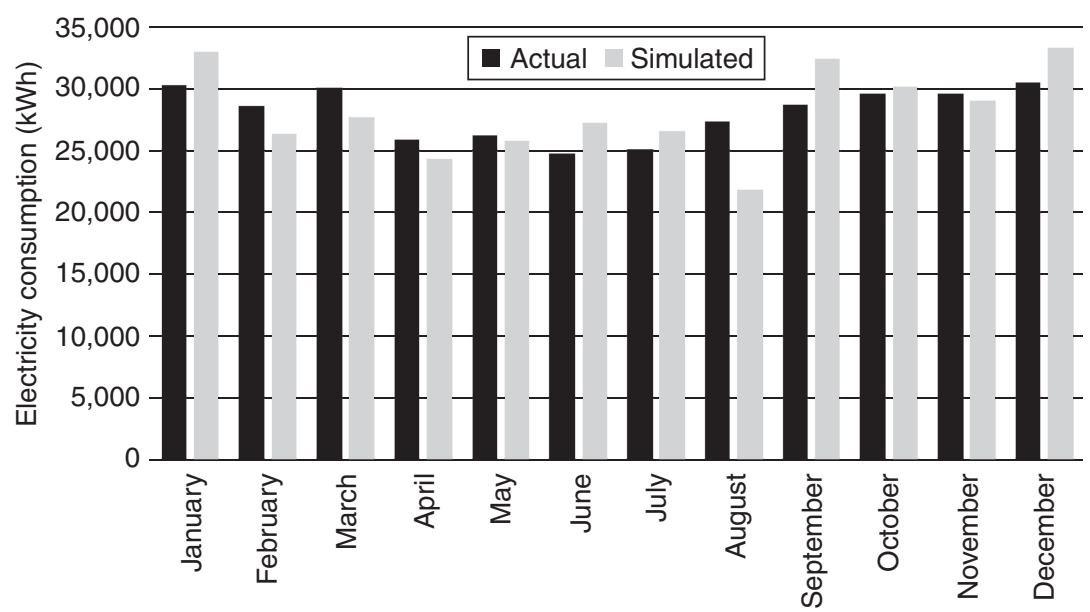

Figure 6. Comparison of metered and simulated electricity consumption.

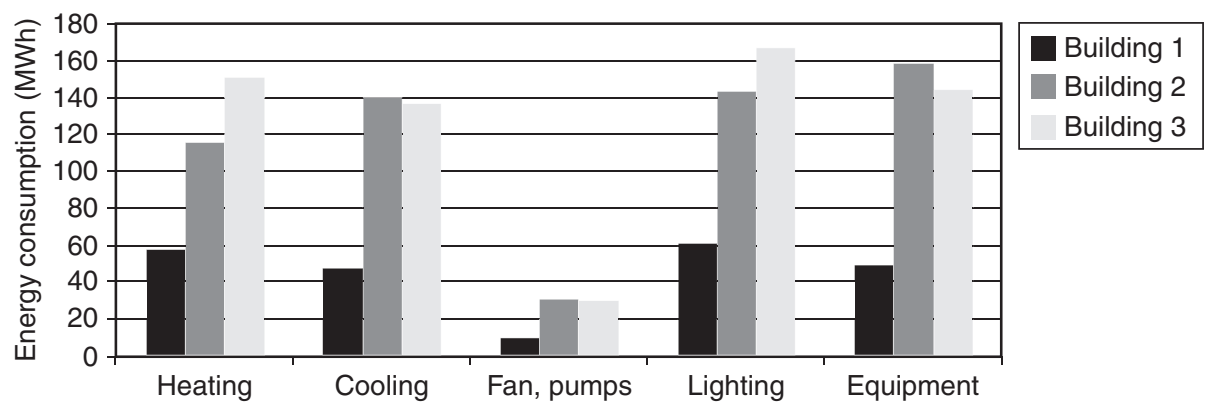

Figure 7. Energy consumption by sub-systems.

equipment. In addition, the energy consumption by each functional area was analysed. All the three buildings showed similar profiles. Figure 7 shows the energy consumption by various sub-systems. Heating and cooling together constitute $44-47 \%$, while lighting constitutes $24-27 \%$. Equipment energy consumption is $22-27 \%$ which is normal for health facility. Energy consumption of $24 \%$ for lighting is comparable to large hospitals and this shows the potential savings through more responsive design. As discussed earlier, building 2 has no dimming system or daylight sensors despite the additional daylight features such as skylight; hence there is saving potential through more responsive design. Ascione et al. [17] investigated energy saving potential of envelope rehabilitation for a day hospital building in Naples, Italy, and found that the HVAC systems energy reduced up to $50 \%$ and improved indoor thermal conditions. The results of bundled energy efficiency measure analysis for small hospitals and healthcare centres [4] show that biggest energy savers are the Lighting Power Density (LPD) reductions and the implementation of a zone airflow setback. 
Table 7. Load contribution of different components

\begin{tabular}{lcccc}
\hline Load type & Envelope & Light+Equipment & People & Outside air \\
\hline Heating & $44.5 \%$ & $22.19 \%$ & $6.4 \%$ & $26.86 \%$ \\
Cooling & $16.1 \%$ & $66.87 \%$ & $6.2 \%$ & $7.84 \%$
\end{tabular}

Table 8. Energy usage of functional spaces

\begin{tabular}{lccc}
\hline Functional spaces & Area $\left(\mathbf{m}^{\mathbf{2}}\right)$ & Energy $(\mathbf{k W h})$ & $\begin{array}{c}\text { Energy per } \\
\text { unit area } \\
\left.\mathbf{( k W h} / \mathbf{m}^{\mathbf{2}}\right)\end{array}$ \\
\hline Circulation and office & 768 & 143 & 186.09 \\
Mental health & 279 & 93 & 332.81 \\
Community health and physio & 335 & 111 & 331.02 \\
Dental & 343 & 110 & 320.41 \\
Renal & 230 & 112 & 487.93
\end{tabular}

The main sources of the HVAC load are energy transfer across building envelope such as walls, windows, and roofs, and heat generation from people and equipment. A closer look at the load components for heating and cooling for building 2 revealed that majority (45\%) of the heating load is from envelope in which $20 \%$ is from windows and $13.5 \%$ is from walls (see Table 7). For cooling load, $37 \%$ is from equipment and $16 \%$ is from envelope. This is due to the increased heat output form the equipment. Comparing with the other two buildings it can be seen that the total window-wall ratio doesn't have much correlation with the envelope load either in winter or summer. The window area for each orientation may be a better basis for comparison. Murray et al. [9] attributed such poor correlation between energy consumption and building fabric in NHS Scotland buildings to the variations in daily operational routines.

Table 8 shows the energy consumption by different functional areas. Circulation and office area consume a minimum $186 \mathrm{kWh}$ per unit area whereas renal area consumes a maximum $488 \mathrm{kWh}$ per unit area.

\section{CONCLUSION}

This paper investigated the energy performance of three medium-sized healthcare buildings located in the moderate climatic zone in Victoria, Australia. The buildings were operated by the same healthcare organisation and were quite similar with respect to the types of functional space, but there were slight variations in the provision of specialist services. The total energy usage intensity of the three buildings ranged from 167 to $306 \mathrm{kWh} / \mathrm{m}^{2}$. Some of the potential drivers of energy consumption were determined to identify the key indicators. The building with a renal unit had highest gas and water consumption. The thermal comfort requirements 
of staff and patients differ considerably, which have a significant impact on gas consumption. Initial survey showed that relatively lower energy consumption of one of the buildings is actually due to compromised thermal comfort. Further onsite thermal comfort measurement is required to evaluate this situation.

This paper highlights the importance of setting up benchmarks for the fast growing number of medium-sized health facilities in Australia. Comparison with international standards shows that there is a possibility to achieve lower energy consumption in Victorian healthcare buildings. Careful considerations of daylighting provision would have significant impact on the outcome. The wide difference of energy consumption between offices and renal area, $186 \mathrm{vs.} 488 \mathrm{kWh} / \mathrm{m}^{2}$, suggests the importance of a more integrated HVAC systems.

This study emphasizes that when considering energy saving potential of any healthcare facility, the well-being of patients and safety of hospital staff must not be compromised. Energy efficiency of small and medium scale health buildings is largely disregarded by authorities and facility managers worldwide, and the development of good practice benchmarks is a good starting point to reduce the impact of health services on environment.

\section{CONFLICT OF INTEREST}

We certify that there is no conflict of interest with any organization regarding the material discussed in the manuscript.

\section{REFERENCES}

[1] Renedo CJ, Ortiz A, Mañana M, Silio D, Pe'rez S, Study of different cogeneration alternatives for a Spanish hospital Center, Energy and Buildings, 2006, 38:484-490.

[2] Vanhoudta D, Desmedta J. Van Baela J, Robeyn N, Hoes H (2011), An aquifer thermal storage system in a Belgian hospital: Long-term experimental evaluation of energy and cost savings, Energy and Buildings, 2011, 43: 3657-3665.

[3] Bonnema E, Doebber I, Pless S, Torcellini P, Technical Support Document: Development of the Advanced Energy Design Guide for Small Hospitals and Healthcare Facilities - 30\% Guide , National Renewable Energy Laboratory, 2010.

[4] Bonnema E, Pless S and Doebber I, Advanced energy design guide for small hospitals and healthcare facilities, Journal of Healthcare Engineering , 2010, 1 (2): 277-296.

[5] NHS Sustainable Development Unit Saving Carbon, Improving Health. NHS Carbon Reduction Strategy for England, NHS Sustainable Development Unit, Cambridge, 2009.

[6] Aspinall P, Benchmarking and Best Practice - Energy Management for Healthcare in the UK, Business Briefing: Hospital Engineering \& Facilities Management, 2014.

[7] Short A and Almaiyah S, Design strategy for low-energy ventilation and cooling of hospitals, Building Research \& Information, 2009, 37(3): 264-292.

[8] Short A, Cook M, Cropper P and Almaiyah S Low energy refurbishment strategies for health buildings, Journal of Building Performance Simulation , 2010: 1-20.

[9] Giridharan R, Lomas KJ. Short CA, Fair AJ, Performance of hospital spaces in summer: A case study of a 'Nucleus'-type hospital in the UK Midlands, Energy and Buildings , 2013, 66: 315-328.

[10] Murray J, Pahlb O, Burek S, Evaluating the scope for energy-efficiency improvements in the public sector: Benchmarking NHSScotland's smaller health buildings, Energy Policy, 2008, 36: 1236-1242.

[11] Oliver-Solà J, Armero M, Martinez de Foix B, Rieradevall J, Energy and Environmental Evaluation of Municipal Facilities: Case study in the province of Barcelona, Energy Policy, 2013, 61:920-930. 
[12] Australian Institute of health and welfare, Public health expenditure in Australia, November 2009.<http://www.aihw.gov.au/publications/hwe/hwe-47-10952/hwe-47-10952.pdf> accessed 9th September 2010.

[13] Australian Greenhouse office, Australian Commercial Building Sector Greenhouse Gas Emissions 1990-2010.

[14] Connor A, Lillywhite R, Cooke M.J, The carbon foorprint of a renal service in United Kingdom, QJM, An international Journal of Medicine, 2010, 103 (12): 965-975

[15] Agar JWM., Simmonds RE., Knight R, Using water wisely: new affordable, and essential water conservation practices for facility and home haemodialysis, Hemodialysis International, 200913: 32-37.

[16] IES Microflow (CFD) user guide, Virtual Environment 6.0, Integrated Environmental Solutions Limited.

[17] Ascione F, Bianco N, De Masi RF, Vanoli GP, , Rehabilitation of the building envelope of hospitals: Achievable energy savings and microclimatic control on varying the HVAC systems in Mediterranean climates, Energy and Buildings, 2013, 60:125-138. 


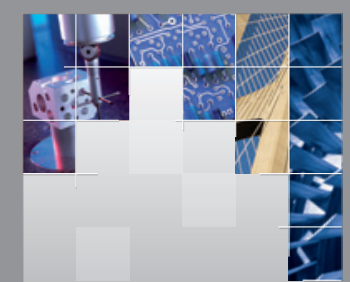

\section{Enfincering}
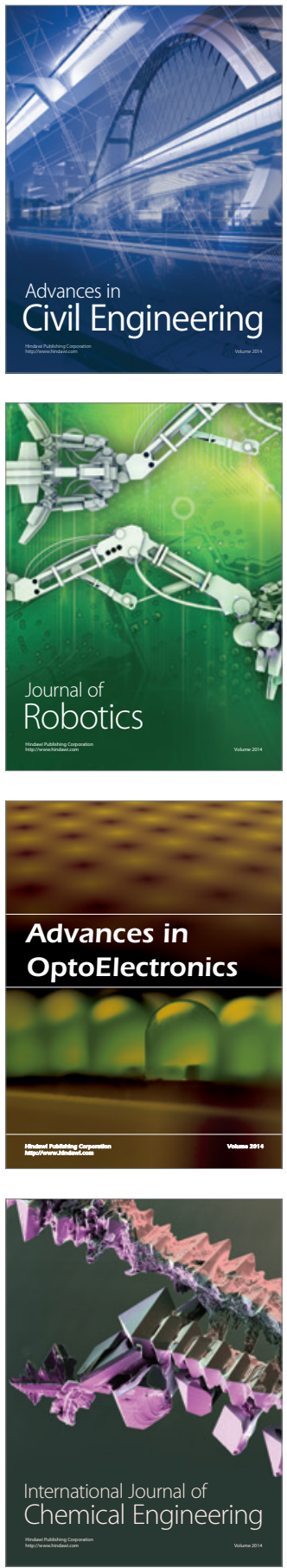

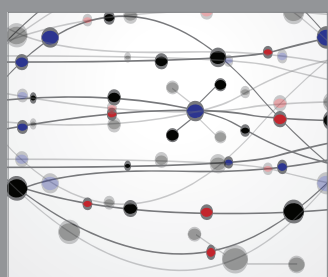

The Scientific World Journal

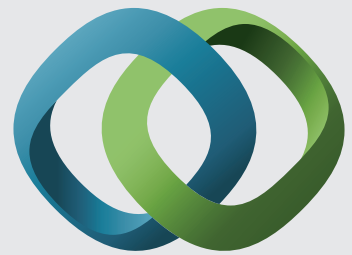

\section{Hindawi}

Submit your manuscripts at

http://www.hindawi.com
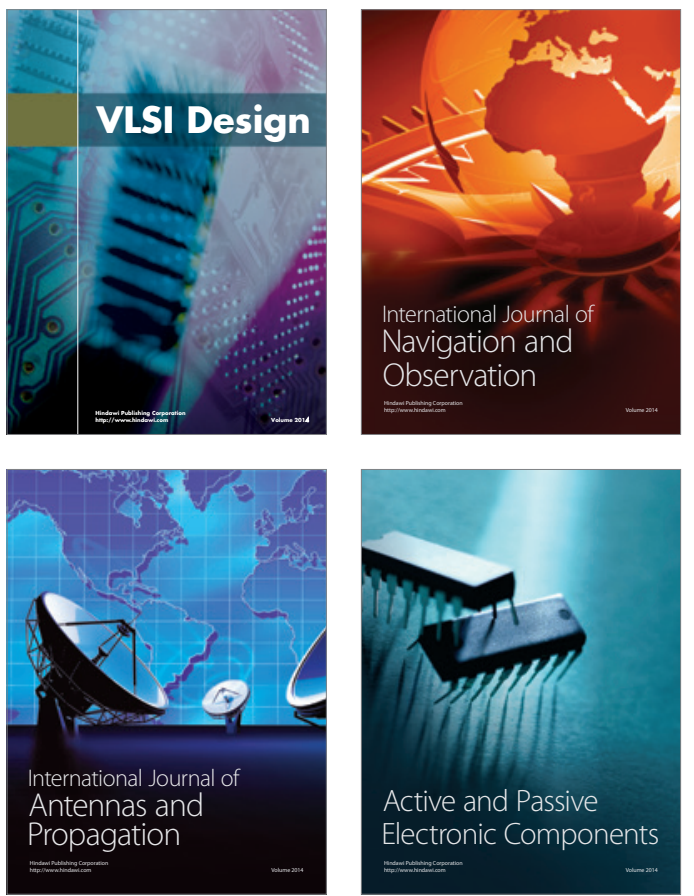
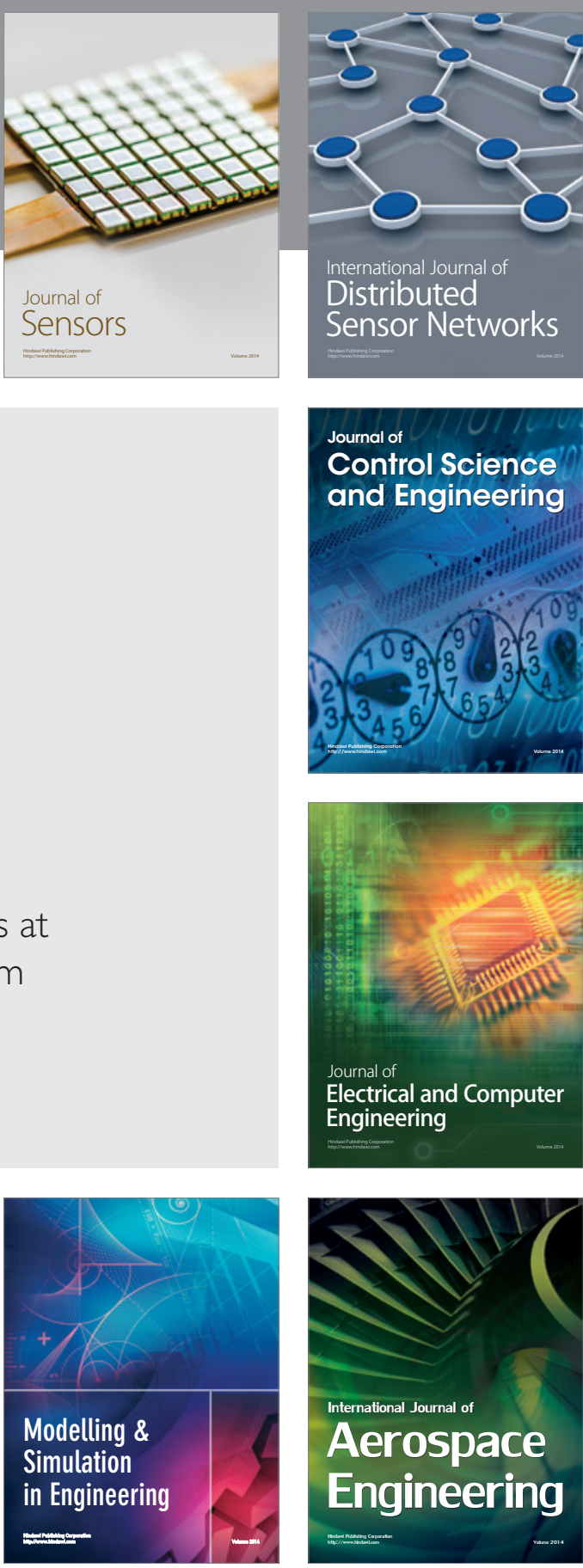

International Journal of

Distributed

Sensor Networks

Journal of

Control Science

and Engineering
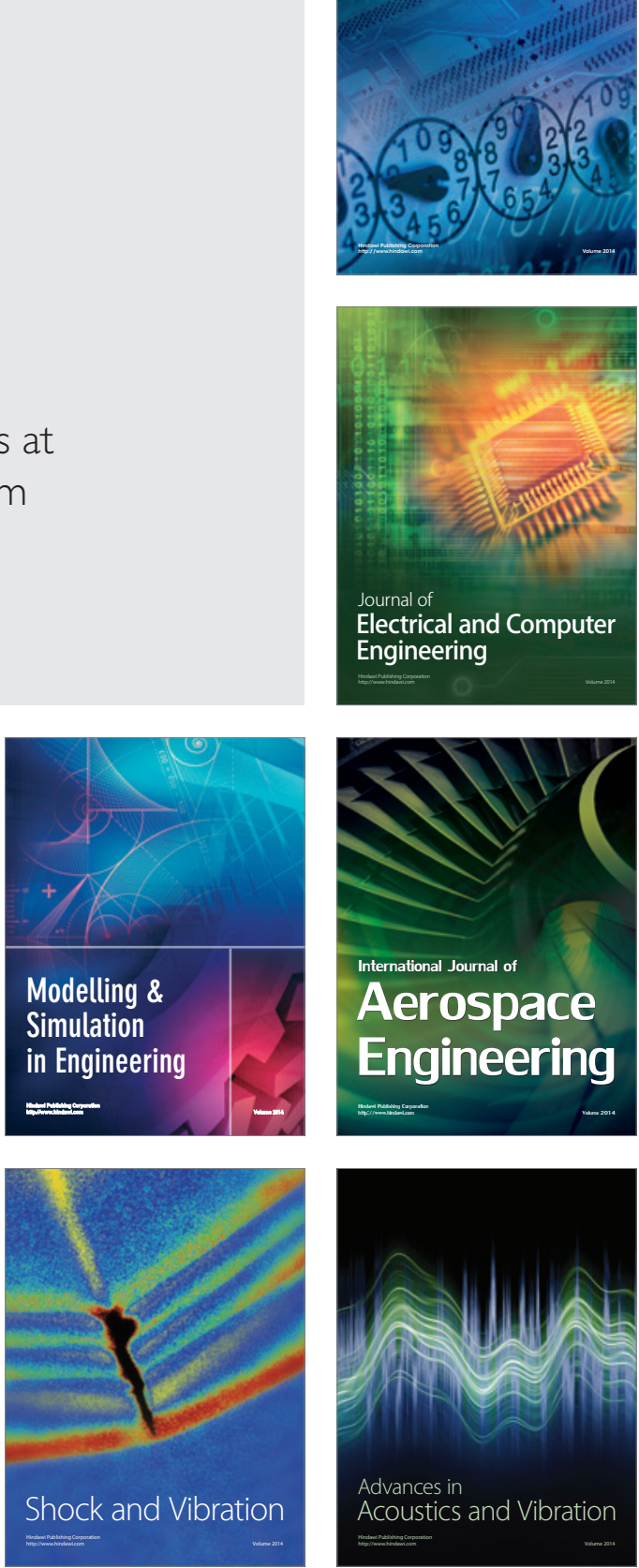